\title{
An Anthropometric Evaluation of Morphological Facial Height in Bangladeshi Young Adult
}

\author{
Sheikh MA ${ }^{1}$, Chowdhury $\mathrm{GM}^{2}$, Jolly $\mathrm{F}^{3}$, Zaman $\mathrm{M}^{4}$
}

\begin{abstract}
Introduction: Anthropometry is applied to obtain measurements of living subjects for identifying age, stature, proportions body and/ or face and various dimensions related to particular race or an individual. Facial anthropometric studies have got vast implications in health related fields and are useful for orthodontists, plastic surgeons, maxillofacial surgeons for their treatment plans to evaluate treatment prognosis and determine treatment outcome. Prior to advent of cephalometric radiography, orthodontists often used anthropometric measurements to establish facial proportion. Although for orthodontists, this method was largely replaced by cephalometric analysis for many years, the recent emphasis on soft tissue proportions has brought soft tissue evaluation back into prominence. When there are questions about vertical facial proportions, it is better to make the measurement clinically rather than cephalometric analysis, because the soft tissue proportions, as seen clinically determine the facial appearance.
\end{abstract}

Objective: To evaluate morphological facial height and to establish the upper \& lower facial height proportions in Bangladeshi adult and to compare with similar data of various nations \& ethnic groups.

Method: This study was a descriptive observational cross sectional study by convenient sampling, conducted in AFMI (Armed Forces Medical Institute) among the 500 participants of Bangladeshi by birth with equal sex distribution aged 18-25 years. The anthropometric landmarks the nasion(n), subnasale (sn) and ganthion (gn), were marked on the participant's face with a dermographic pen. With the help of a digital vernier sliding calipers, the measurements were taken in millimeters and the participant was in centric relation when measuring the facial height. The distance from ' $n$ ' to 'sn' is upper facial height (UFH), from 'sn' to 'gn' is lower facial height (LFH) and total facial height (TFH) is the sum of UFH and LFH.

Conclusion: There is strong correlation among upper, lower and total facial height. The facial height proportion found in this study matches with ideal facial proportion widely practiced in clinical orthodontics for treatment planning and to determine treatment outcome. The findings of this study may help to establish the norms of facial proportion in Bangladeshi adult which will be helpful for treatment planning in orthodontic and reconstructive surgery without chephalomtric means.

Key-words: Anthropometry, morphological facial height, upper and lower facial height proportion.

\section{Introduction}

Prior to advent of cephalometric radiography, orthodontists often used anthropometric measurements to establish facial proportion. Although for orthodontists, this method was largely replaced by cephalometric analysis for many years, the recent emphasis on soft tissue proportions has brought soft tissue evaluation back into prominence. When there are questions about vertical facial proportions, it is better to make the measurement clinically rather than cephalometric analysis, because the soft tissue proportions, as seen clinically, determine the facial appearance ${ }^{1}$.

1. Lt Col Md. Asaduzzaman Sheikh, BDS, MCPS, FCPS, Graded Spl in Orthodontics and Dentofacial Orthopedics, CMH, Dhaka Cantt; 2. Brig Gen Golam Mohiuddin Chowdhury, BDS, FCPS, Adv in Dentistry, CMH, Dhaka Cantt.

3. Asst Prof Ferdousy Jolly, BSc (Hons), MSc (Nutrition), Department of Nutrition, Home Economics College, Azimpur, Dhaka. 4. Maj Moniruzzaman, BDS, FCPS, Dental Surgeon, $\mathrm{CMH}$, Comilla Cantt. 
The importance of seeing the face in proportions has been emphasized by many orthodontists and surgeons $^{2-12}$. These proportions were described by various canons in ancient Greece which were established by anthropometric measurements and artistic norms ${ }^{13}$. These norms and proportions are very important guidelines for treatment planning in orthodontics, dentofacial orthopedics and reconstructive surgery. Physical anthropological methodologies, though neglected by many clinicians ${ }^{14}$ but many orthodontic researches have already shown its usefulness ${ }^{15-19}$. Its application in reconstructive surgery is even more justified since the soft tissue morphology of the face cannot be studied reliably from cephalogram of underlying skeleton in certain areas ${ }^{20-21}$.

Facial anthropometry ${ }^{22}$ describes two types of face height, namely: Physiognomic facial height (trichiongnathion) and Morphological face height (nasiongnathion). Physiognomic face is divided into three parts, such as upper face (trichion-glabella), middle face (glabella - subnasale) lower face (subnasalegnathion). Morphological face is divided into upper face (nasion- subnasale) and lower face (subnasale - gnathion).

With the rapid advancement in techniques of correcting multiple facial anomalies by orthodontics, dentofacial orthopedics and orthognatic surgical means, the treatment planning has become more sophisticated and the knowledge of exact relationship between various areas of head and face is now indispensable ${ }^{23}$. The purpose of this study is to evaluate morphological facial height and to establish the upper \& lower facial height proportions in Bangladeshi adult and to compare with similar data of various nations \& ethnic groups.

The available anthropometric values related to this study are limited to Caucasians and, there is a little data available for Asians. Moreover, there is no available standard data regarding morphological facial height and its proportion in our country. So it is essential to address the scientific data to correlate facial height and to establish facial proportion among the Bangladeshi adult population. Reliable and comparable data is needed to evaluate the facial height proportions for orthodontics, dentofacial orthopedic, orthognatic and reconstructive maxillofacial surgery for treatment planning and to evaluate the treatment outcome. So an attempt has been made through this study to aid in establishing a Bangladeshi norms regarding morphological facial height proportion which will be a guideline in orthodontic treatment planning.

\section{Materials and Methods}

This study was a descriptive observational cross sectional study by convenient sampling, conducted among 500 participants of Bangladeshi by birth with equal sex distribution aged 18-25 years. The sample populations were the BSc Nursing and Para-medical students of Armed Forces Medical Institute, troops of Bangladesh Army and Airmen of Bangladesh Air Force at Dhaka Cantonment.

Exclusion criteria was any cranio-facial abnormalities, Growth-related disorders, genetic abnormalities, prolonged diseases such as congenital heart diseases, endocrine, renal and intestinal disorders, history of facial trauma, those belonging to intermingling communities (i.e. whose parents and grandparents had inter-caste marriages), history of previous orthodontic and craniofacial surgical treatment, gummy smile, deep bite \& open bite and subjects with visible abnormality.

The landmarks of the study were defined as follows:

- Nasion-The point on the roof of the nose where the mid-sagittal plane cuts the nasofrontal suture.

- Subnasale-It is the junction between the lower border of the nasal septum, the partition which divides nostrils, and the cutaneous portion of the upper lip the mid line.

- Gnathion-The lowest point in the mid line on the lower border of the chin. 


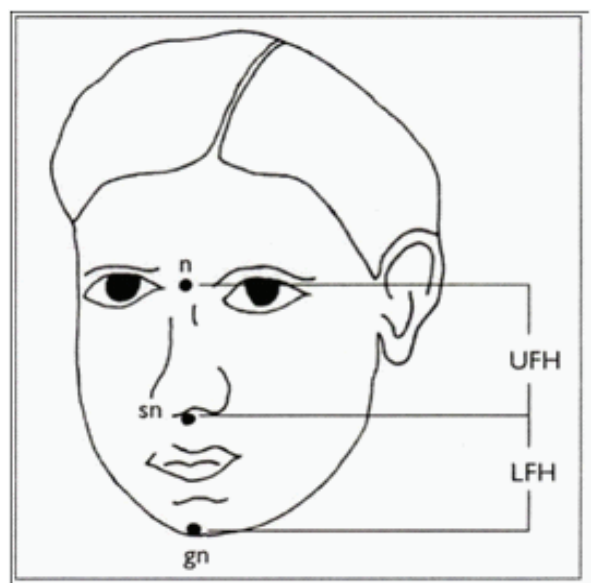

Fig-1: Anthropometric landmarks and measurements on the human face.

Each participant was made to sit on a wooden chair. The anthropometric landmarks- the nasion(n), subnasale (sn) and ganthion (gn) were marked on the participant's face with a dermographic pen. With the help of a digital vernier sliding calipers, the measurements were taken in millimeters and the participant was in centric relation when measuring the facial height. A repeat measurement was taken for each participant. If the two measurements disagree by more than $0.5 \mathrm{~mm}$, then a third measurement was taken.

The participant's measured height was subsequently calculated as the mean of the two observations or the mean of the two closest measurements if a third was taken. When necessary to round the mean value to the nearest $0.1 \mathrm{~cm}$, rounding was to the nearest even digit. The distance from ' $n$ ' to ' $s n$ ' is upper facial height (UFH), from 'sn' to 'gn' is lower facial height ( $\mathrm{LFH}$ ) and total facial height (TFH) is the sum of UFH and LFH. Paired "T" was done for gender significance and Pearson's correlation coefficient test were used for individual for combination of TFH to UFH and LFH to find out correlation among them. The criteria for statistical significance were set at $p<0.05$ and $\mathrm{Cl}$ 95\%.

\section{Results}

This descriptive observational cross sectional study was conducted on 500 participants with equal sex distribution in Armed Forces Medical Institute with a view to aid in establishing Bangladeshi norms of morphological height proportion.
Table-I shows linear measurement of lower facial height, upper facial height and total morphological facial height in both sexes. It was found that LFH was $69.58 \pm 3.51$ and $62.76 \pm 3.03$, UFH was $57.68 \pm 3.23$ and $49.94 \pm 4.19$ and $\mathrm{TFH}$ was $127.22 \pm 6.12$ and $112.70 \pm 6.04$ for males and females respectively. Two sample ' $t$ ' test with equal variances was done and found statistically significant $(p<0.05)$.

Table-I: Distribution of morphological facial height parameters in both sexes $(n=500)$.

\begin{tabular}{|l|l|l|l|}
\hline Sex & $\begin{array}{l}\text { LFH }(\mathrm{mm}) \\
(\text { Mean } \pm \text { SD) }\end{array}$ & $\begin{array}{l}\text { UFH }(\mathrm{mm}) \\
(\text { Mean } \pm \text { SD })\end{array}$ & $\begin{array}{l}\text { TFH }(\mathbf{m m}) \\
(\text { Mean } \pm \text { SD })\end{array}$ \\
\hline Male & $69.58 \pm 3.51$ & $57.68 \pm 3.23$ & $127.22 \pm 6.12$ \\
\hline Female & $62.76 \pm 3.03$ & $49.94 \pm 4.19$ & $112.70 \pm 6.04$ \\
\hline P-value & 0.0001 & 0.0001 & 0.0001 \\
\hline
\end{tabular}

*LFH-Lower facial height, ULFH-Upper facial height, TFH-Total facial height

Table-Il shows components of morphological facial height proportions in percentage. It was found that LFH was $54.68 \%$ and $55.73 \%$; UFH was $45.32 \%$ and $44.27 \%$ for males and females respectively.

Table-II: Distribution of upper and lower facial height in percentage in both sexes $(n=500)$.

\begin{tabular}{|l|c|c|}
\hline Sex & LFH & UFH \\
\hline Male & $54.68 \%$ & $45.32 \%$ \\
\hline Female & $55.73 \%$ & $44.27 \%$ \\
\hline
\end{tabular}

Table-III shows strong statistical significant correlation among upper, lower and total facial height

Table-III: Pearson's correlation coefficient test $(n=500)$.

\begin{tabular}{|l|l|l|l|l|}
\hline & & UFH & LFH & TFH \\
\hline \multirow{3}{*}{ Total } & UFH & 1.0000 & & \\
\cline { 2 - 5 } & LFH & $0.7628^{\star}$ & 1.0000 & \\
\cline { 2 - 5 } & TFH & $0.9465^{\star}$ & $0.9285^{\star}$ & 1.0000 \\
\hline \multirow{3}{*}{ Male } & UFH & 1.0000 & & \\
\cline { 2 - 5 } & LFH & $0.6681^{\star}$ & 1.0000 & \\
\cline { 2 - 5 } & TFH & $0.9034^{*}$ & $0.9134^{*}$ & 1.0000 \\
\hline \multirow{3}{*}{ Female } & UFH & 1.0000 & & \\
\cline { 2 - 5 } & LFH & $0.3835^{\star}$ & 1.0000 & \\
\cline { 2 - 5 } & TFH & $0.8860^{*}$ & $0.7681^{*}$ & 1.0000 \\
\hline
\end{tabular}

Table-IV(a) \& Table-IV(b) show international comparison of various components of morphological facial height in linear and in percentage among various nations and ethnic groups. 
Table-IV(a): International comparison of components morphological facial height for male ${ }^{30}$.

\begin{tabular}{|l|c|c|c|c|c|}
\hline Nationality & $\begin{array}{c}\text { TFH(mm)-n- } \\
\text { gn } \\
\text { (Mean) }\end{array}$ & $\begin{array}{c}\text { LFH(mm)-sn- } \\
\text { gn } \\
\text { (Mean) }\end{array}$ & LFH\% & $\begin{array}{c}\text { UFH(mm)-n- } \\
\text { sn } \\
\text { (Mean) }\end{array}$ & UFH\% \\
\hline Bangladeshi & 127.20 & 69.50 & 54.68 & 57.7 & 45.32 \\
\hline India & 112.50 & 62.70 & 55.73 & 49.8 & 44.26 \\
\hline Japanese & 122.80 & 69.40 & 56.51 & 53.4 & 43.00 \\
\hline Vietnamese & 121.20 & 71.10 & 58.66 & 50.1 & 41.33 \\
\hline Thai & 123.50 & 72.40 & 58.62 & 51.1 & 41.37 \\
\hline Singaporean Chinese & 123.60 & 72.80 & 58.89 & 50.80 & 41.10 \\
\hline North American White & 121.30 & 71.90 & 59.27 & 49.4 & 40.72 \\
\hline Azerbaijan & 121.30 & 69.00 & 56.88 & 52.3 & 43.11 \\
\hline Bulgarian & 122.90 & 69.50 & 56.55 & 53.4 & 43.44 \\
\hline Czech & 117.50 & 70.70 & 60.17 & 46.8 & 39.82 \\
\hline Croatian & 119.80 & 66.00 & 55.09 & 53.8 & 44.90 \\
\hline German & 116.00 & 67.90 & 58.53 & 48.1 & 41.46 \\
\hline Greek & 120.00 & 65.80 & 54.83 & 54.2 & 45.16 \\
\hline Hungarian & 120.00 & 64.20 & 53.50 & 55.80 & 46.50 \\
\hline Italian & 124.70 & 71.40 & 57.25 & 53.30 & 42.74 \\
\hline Polish & 117.50 & 68.10 & 57.95 & 49.40 & 42.04 \\
\hline Portuguese & 124.50 & 69.60 & 55.90 & 54.90 & 44.09 \\
\hline Russian & 122.90 & 64.50 & 52.48 & 58.40 & 47.51 \\
\hline Iranian & 132.40 & 73.30 & 55.36 & 59.10 & 44.63 \\
\hline Turkish & 127.70 & 65.90 & 51.60 & 61.80 & 48.39 \\
\hline Egyptian & 116.40 & 64.10 & 55.06 & 52.30 & 44.93 \\
\hline Angolan & 112.10 & 67.30 & 60.03 & 44.80 & 39.96 \\
\hline Afro-American & 125.90 & 78.90 & 62.66 & 47.40 & 37.33 \\
\hline Zulu & 121.80 & 72.20 & 59.27 & 49.60 & 40.72 \\
\hline
\end{tabular}

Table-IV(b): International comparison of components of morphological facial of female ${ }^{30}$.

\begin{tabular}{|l|c|c|c|c|c|}
\hline Nationality & $\begin{array}{c}\text { TFH(mm)-n- } \\
\text { gn } \\
\text { (Mean) }\end{array}$ & $\begin{array}{c}\text { LFH(mm)-sn- } \\
\text { gn } \\
\text { (Mean) }\end{array}$ & LFH\% & $\begin{array}{c}\text { UFH(mm)-n- } \\
\text { sn } \\
\text { (Mean) }\end{array}$ & UFH\% \\
\hline Bangladeshi & 112.70 & 62.70 & 55.73 & 49.90 & 44.27 \\
\hline India & 113.80 & 64.40 & 56.59 & 49.40 & 43.40 \\
\hline Japanese & 113.80 & 62.80 & 55.18 & 51.00 & 44.81 \\
\hline Vietnamese & 113.10 & 64.00 & 56.58 & 49.10 & 43.41 \\
\hline Thai & 112.80 & 62.60 & 55.49 & 50.20 & 44.50 \\
\hline Singaporean Chinese & 114.90 & 66.40 & 57.78 & 48.50 & 42.21 \\
\hline North American White & 118.80 & 65.50 & 58.58 & 46.30 & 41.41 \\
\hline Azerbaijan & 111.50 & 63.60 & 57.04 & 47.90 & 42.95 \\
\hline Bulgarian & 111.00 & 61.60 & 55.49 & 49.40 & 44.50 \\
\hline Czech & 112.60 & 66.00 & 58.61 & 46.60 & 41.38 \\
\hline Croatian & 110.40 & 60.70 & 54.98 & 49.70 & 45.01 \\
\hline German & 1109.5 & 63.30 & 57.80 & 46.20 & 42.19 \\
\hline Greek & 116.40 & 63.30 & 54.38 & 53.10 & 45.61 \\
\hline Hungarian & 112.40 & 56.70 & 50.44 & 55.70 & 49.55 \\
\hline Italian & 113.80 & 64.40 & 56.59 & 49.40 & 43.40 \\
\hline Polish & 111.60 & 60.50 & 54.21 & 51.10 & 45.78 \\
\hline Portuguese & 118.20 & 62.80 & 53.13 & 55.40 & 46.86 \\
\hline Russian & 114.20 & 61.40 & 53.76 & 52.80 & 46.23 \\
\hline Iranian & 120.30 & 66.20 & 55.02 & 54.10 & 44.97 \\
\hline Turkish & 116.40 & 59.10 & 50.77 & 57.30 & 49.22 \\
\hline Egyptian & 103.10 & 57.80 & 56.06 & 45.30 & 49.93 \\
\hline Angolan & 106.50 & 63.20 & 59.34 & 43.30 & 40.65 \\
\hline Afro-American & 116.50 & 71.50 & 61.37 & 45.00 & 38.62 \\
\hline Zulu & 113.70 & 65.40 & 57.51 & 48.30 & 42.48 \\
\hline
\end{tabular}




\section{Discussion}

A single standard facial aesthetics is not appropriate for all racial and ethnic groups and a normative data of facial measurements are essential for precise determination of the degree of variation from the normal ${ }^{24,25}$. Morphometric study for the facial relations and variations in humans have long been used to differentiate in various racial groups in physical anthropology ${ }^{26}$. Moreover morphological characteristics are an important factor to be considered in the diagnosis and treatment planning in orthodontics \& dentofacial orthopaedics ${ }^{27}$. Whenever we examine a patient for orthodontic treatment, our prime concern would be only on the face. The measurement of the upper, lower and total facial height is a routine aspect of clinical examination in orthodontic practice.

Clinical anthropometry has recently undergone a revival because of current data provided by Farkas in his studies of Canadians of North European origin, where he found that LFH and UFH constitute $59.5 \%$ and $40.5 \%$ of $\mathrm{TFH}$ respectively ${ }^{28}$. In this study, LFH is $54.7 \%$ and $55.75 \%$ of $\mathrm{TFH}$ for males and females respectively which was found comparatively lower than that of Canadians of North European origin. The ideal proportions of UFH and $\mathrm{LFH}$ had been found to be $45 \%$ and $55 \%$ of the $\mathrm{TFH}$, respectively ${ }^{28}$. In another study, Farkas et al found a lower face / face height ratio of $59.2 \% \pm 2.7$ $\%$ in male $58.6 \% \pm 2.9 \%$ in female subjects. LFH is $54.7 \%$ and $55.75 \%$ of $\mathrm{TFH}$ males and females respectively in this study. Thus, the percentage of LFH was found to be lowered when compared to the findings of Farkas et al's study ${ }^{29}$. These differences may be attributed to differences in the study populations, genetic and ethnic diversifications.

For the evaluation of distributional differences among the measurement values in ethnic groups (Caucasians of Europe, ethnic groups in Middle East, Asia and Africa) the data base of the North American whites (NAWs) populations was used as a reference group ${ }^{30}$. The lower facial height (sn-gn) in Hungarian females was extremely and Slovakian females very significantly smaller. In the three Middle Eastern male groups the measurements are identical to those of NAWs. In the females the measurements were identical with NAWs in Turkis only. Morphological facial height in Iranian females was very significantly greater while both face height and lower face height were very significantly smaller in Egyptian females. In almost all Asians males and females ethnic groups measurements were almost identical to NAWs. Of the African ethnic groups, the Zulus and Afro-Americans showed identical facial measurements compared with NAWs in both sexes $^{30}$. The variations of anthropometric measurements among the internationals may be due to genetic, racial and ethnic variations.

\section{Conclusion}

There is strong correlation among upper, lower and total facial height. The lower facial height proportion is $54.68 \%$ and $55.73 \%$ and the upper facial height proportion is $45.32 \%$ and $44.32 \%$ to total facial height for male and female respectively. The facial height proportion found in this study matches with ideal facial proportion widely practiced in clinical orthodontics for treatment planning and to determine treatment outcome. The findings of this study may help to establish the norms of facial proportion in Bangladeshi adult which will be helpful for treatment planning in orthodontic and reconstructive surgery without chephalomtric means.

\section{Reference}

1. Profit WR, Fields HW. Contemporary Orthodontics. 4th ed. St. Louis: Mosby; 2007: 177.

2. Broadbent TR, Mathews VL. Artistic relationships in surface anatomy of face: Application to reconstructive surgery. Plast. Reconstr. Surg. 1957; $20: 1$.

3. Karfic $V$ et al. Plastic Surgery of the Injured Face. 1st ed. Prague: State Health Publishing House; 1961: 263-9.

4. Seghers MJ, Loggacre JJ and DeStefano GA. The golden proportion and beauty. Plast. Reconstr. Surg. 1964; 34:382-7.

5. Burian F. Problems of the Facial Clefts. 2nd ed. Prague: Czechoslovac Academy of Science; 1971: 20.

6. Frmn F, Coccaro PJ, and Converse JM. Cephalometric analysis in diagnosis and treatment planning of craniofacial dysostoses. . Plast. Reconstr. Surg. 1974; 54:300-4. 
7. Belinfante LS. Disproportion of facial height: Report of cases. J. Oral Surg. 1976; 34: 385-9.

8. Converse JM. (Ed.). Reconstructive Plastic Surgery Vol. 3. 2nd ed. Philadelphia: Saunders; 1977: 32-7.

9. Patterson CN. Surgery to the Aging Nose. In G. A. Sisson and M. E. Tardy (Eds.) Plastic and Reconstructive Surgery of the Face and Neck. 1st ed. New York: Grunne \& Stratton; 1977: 21.

10. Lee $L$ and Lee KJ. A study of Facial proportions sketching of facial contours. Ear Nose Throat J. 1979; 58: 150-55.

11. Maue-Dickson W. The craniofacial complex in cleft lip and palate: An updated review of anatomy and function. Cleft Palate J. 1979; 16: 291-4.

12. Stoksted P and Gutierrez C. Facial morphology applied to rhinologic surgery. J. Laryngol. Oto. 1981; 95: 693-9.

13. Farkas LG, Hreczko TA, Mounro IR and Kolar JC. Vertical and horizontal proportions of the face in the young adults North American Caucasians: revision of neoclassical canons. Plast Reconstr Surg. 1985; 75: 328-38.

14. Hrdlicka A. Anthropometry. Philadelphia: Wistar institute, 1920.

15. Hellman M. Some facial features and their orthodontic implications. Am. J. Orthodont. 1939; 25: 927-32.

16. Gosman SD. Anthropometric method of facial analysis in orthodontics. Am. J. Orthodont. 1950; 36: 749-55.

17. Bowker WD and Meredith HV. A metric analysis of facial profile. Angle Orthod. 1959; 29:149-58.

18. Elsaser W A. Studies of dentofacial morphology. A simple instrument for apprising variations. Angle Orthod. 1951; 21:163-8.

19. Hershey $H G$ and Smith LH. Soft tissue profile change associated with surgical correction of prognathic mandible. Am. J. Orthodont. 1974; 65: 483-98.
20. Subtelny JD. A longitudinal study of soft tissue facial structures and their profle characteristics, defined in relation to underlying skeletal structures. Am. J. Orthodont. 1959; 45: 481-95.

21. Bloom LA. Perioral profile changes in orthodontic treatment. Am. J. Orthodont. 1961; 47:317-24.

22. Kolar JC and Salter EM. Craniofacial anthropometry.1st ed. Springfield, Illinois, USA: Charles C Thomas Publisher Itd; 1997: 102-4.

23. Farkas LG. Anthropometry of the head and face in medicine. 1st ed. New York: Elevier; 1981: 231.

24. Richardson ER. Racial differences in dimensional traits of the human face. Angle Orthod 1980; 50:301-9.

25. Miyajima K, McNamara JA, Kimura T, Murata S and lazuka T. Craniofacial structure of Japanese and European-American adult with normal occlusions and well balanced faces. Am J of Orthod Dentofacial Orthop.1996; 110:431-8.

26. Rizvi HM, Hossian MZ and Tanee K. Ethnical evaluation of Bangladeshi young adults in terms of morphologically-analyzed craniofacial skeleton. APOS trends in Orthodontics. 2013; 3: 15-22.

27. De Freitas LM, Pinzan A, Janson G, et al. Facial height comparison in young white and black Brazilian subjects with normal occlusion. Am J Orthodont. 2007; 131: 706-13.

28. Farkas LG. Facial anthropometric measurements and facial indices. Profit WR, Fields HW, Ackerman JI, et al, eds. Contemporary Orthodontics. 2nd ed. St Louis: Mosby; 1993:144-5.

29. Farkas LG, Katic MJ and Forerst CR. Age related changes in anthropometric measurements in the craniofacial regions and in height in Down's syndrome. J. Craniofac Surg. 2002; 13:614-22.

30. Farkas LG, Katic MJ, Forrest CR. International anthropometric study of facial morphology in various ethnic groups/races. J craniofac Surg.2005; 16(4):615- 46. 